\title{
STUDY OF EFFECTIVENESS OF TIME SERIES MODELING (ARIMA) IN FORECASTING STOCK PRICES
}

\author{
Prapanna Mondal ${ }^{1}$, Labani Shit ${ }^{1}$ and Saptarsi Goswami ${ }^{2}$ \\ ${ }^{1}$ Student, Bachelor of Technology \\ Department of Computer Science and Engineering \\ Institute of Engineering and Management \\ ${ }^{2}$ Asst. Professor \\ Department of Computer Science and Engineering \\ Institute of Engineering and Management
}

\begin{abstract}
Stock price prediction has always attracted interest because of the direct financial benefit and the associated complexity. From our literature review, we felt the need of a study having sector specific analysis with a broad range of stocks. In this paper, we have conducted a study on the effectiveness of Autoregressive Integrated Moving Average (ARIMA)model, on fifty six Indian stocks from different sectors. We have chosen ARIMA model, because of its simplicity and wide acceptability of the model. We also have studied the effect on prediction accuracy based on various possible previous period data taken. The comparison and parameterization of the ARIMA model have been done using Akaike information criterion (AIC). The contribution of the paper, are a) coverage of a good number of Indian stocks b) Analysis of the models based on sectors c) Analysis of prediction accuracy based on the varying span of previous period data.
\end{abstract}

\section{KEYWORDS}

Stock price prediction, Indian Stocks, Sector, Time Series, ARIMA.

\section{INTRODUCTION}

A time series is a set of well-defined data items collected at successive points at uniform time intervals. Time series analysis is an important part in statistics, which analyzes data set to study the characteristics of the data and helps in predicting future values of the series based on the characteristics. Forecasting is important in fields like finance, industry, etc. [1] Autoregressive and Moving Average (ARMA) model is an important method to study time series. The concept of autoregressive (AR) and moving average (MA) models was formulated by the works of Yule, Slutsky, Walker and Yaglom [1]. Autoregressive Integrated Moving Average (ARIMA) is based on ARMA Model. The difference is that ARIMA Model converts a non-stationary data to a 
stationary data before working on it. ARIMA model is widely used to predict linear time series data. [3] The ARIMA models are often referred to as Box-Jenkins models as ARIMA approach was first popularized by Box and Jenkins. The general transfer function model employed by the ARIMA procedure was discussed by Box and Tiao (1975) [3]. ARIMA model is often referred to as ARIMAX model when it includes other time series as input variables. [18] Pankratz (1991) refers to the ARIMAX model as dynamic regression. [3] The ARIMA procedure offers great flexibility in univariate time series model identification, parameter estimation, and forecasting.

Stock prices are not randomly generated values rather they can be treated as a discrete time series model and its trend can be analyzed accordingly, hence can also be forecasted. There are various motivations for stock forecasting [12], one of them is financial gain. A system that can identify which companies are doing well and which companies are not in the dynamic stock market will make it easy for investors or market or finance professionals make decisions.

Having an excellent knowledge about share price movement in the future helps the investors and finances personals significantly [2]. Since, it is necessary to identify a model to analyze trends of stock prices with relevant information for decision making, it recommends that transforming the time series using ARIMA is a better approach than forecasting directly, as it gives more accurate results [6]. But only predicting will not help if one cannot figure out the efficiency of the result. Thus, this paper focuses on finding the accuracy of predicted values using ARIMA model on the NSE stocks for various companies from various sectors.

In this paper, we have mainly focused on the amount of accuracy of forecasting stock values for various sectors which will help investors understand the market and make a decision to invest in the stock market. The organization of the paper is as follows. In section II, we discuss about the various applications of ARIMA model. In section III, we provide details about the dataset on which we have conducted our experiment. In section IV, we discuss about our experimental steps in details. Section V shows the experimental results and in section VI we conclude.

\section{RELATED WORKS}

Stock forecasting has been the topic of many surveys and review articles to evaluate the accuracies of different statistical technique [8] [9] [10]. At present most of the study is based on stock market trend prediction using ARIMA-based neural networks [11].[13] ARIMA is used as both analytical and forecasting models in the PACAP-CCER China Database, developed by the Pacific

-Basin Capital Markets (PACAP) Research Center at the University of Rhode Island (USA)and th e SINOFINInformation Service Inc, affiliated with the China Center for Economic Research $(C$ CER) of Peking University (China). [2] ARIMA has been applied to solve real world problems in the stock market by forecasting the stock prices with the top four companies in Nifty Midcap-50 using MATLAB along with performance measure.[15] Combining fuzzy regression model and ARIMA model, fuzzy ARIMA (FARIMA) model was developed for the purpose of forecasting the exchange rate of NT dollars to US Dollars. [16] Another purpose for which ARIMA model have been used was for predicting or forecasting price more specifically electricity price of the next day. Mostly the studies and experiments that were conducted were based on forecasting stock prices of a particular stock, whereas our study emphasizes more on a sector specific study related to stock forecasting. 
International Journal of Computer Science, Engineering and Applications (IJCSEA) Vol.4, No.2, April 2014

\section{Datasets}

We have taken historical data of National Stock Exchange (NSE) fifty six companies from seven sectors, eight companies in each sector from the official website of NSE India [19]. We have taken twenty three months of training data from April 2012 to February 2014 and predicted next months' data. We have also divided our dataset into three different time periods, one is of six months' from September 2013 to February 2014, another is of twelve months' from March 2013 to February 2014 and the other is of eighteen months' from September 2012 to February 2014.

\section{Methodology}

\subsection{STEP I: MODEL SELECTION, FITTING AND FORECASTING:}

4.1.1 Model identification: (ARIMA) model is derived by general modification of an autoregressive moving average (ARMA) model. This model type is classified as $\operatorname{ARIMA}(\mathrm{p}, \mathrm{d}, \mathrm{q})$, where $p$ denotes the autoregressive parts of the data set, $d$ refers to integrated parts of the data set and $q$ denotes moving average parts of the data set and p,d,q is all nonnegative integers.

ARIMA models are generally used to analyze time series data for better understanding and forecasting.Initially, the appropriate ARIMA model has to be identified for the particular datasets and the parameters should have smallest possible values such that it can analyze the data properly and forecast accordingly. [14] The Akaike Information Criteria (AIC) is a widely used measure of a statistical model. It is used to quantify the goodness of fit of the model. When comparing two or more models, the one with the lowest AIC is generally considered to be closer with real data. AICc is AIC with a correction for finite sample sizes.

The AIC does not penalize model complexity as heavily as the BIC (Bayesian Information Criterion) does. [7] Burnham \& Anderson shows that AIC and AICc and BIC all can be derived in the same framework and using AIC/AICc for model selection is theoretically proved to be more advantageous than using BIC for selecting a model. As suggested by Yang (2005) [14], AIC is asymptotically optimal in selecting the model, under the assumption that the true model is not in the candidate set (as is virtually always the case in practice); BIC relies on the assumption that the true model is in the candidate set which makes it asymptotically less optimal. Hence, we preferred checking AICc values of data sets for selecting the model to checking the BIC values for the aforementioned.

According to Box-Jenkins method, in ARIMA (p, d, q) the value of $p$ and $q$ should be 2 or less or total number of parameters should be less than 3 [5]. Therefore, for checking AICc of the model we have only checked for $\mathrm{p}$ and $\mathrm{q}$ values 2 or less. The model with the least AICc value is selected [5]. We are showing our experimental results for model selection for stock of the company "Emami Limited". We have used R [20] for conducting our experiments. 
International Journal of Computer Science, Engineering and Applications (IJCSEA) Vol.4, No.2, April 2014

\begin{tabular}{|l|l|}
\hline MODEL & AICc \\
\hline $0,1,0$ & -2175.07 \\
\hline $0,1,1$ & -2173.66 \\
\hline $1,1,1$ & -2173.29 \\
\hline $2,1,1$ & -2173.59 \\
\hline $2,0,1$ & -2173.03 \\
\hline $2,0,2$ & -2174.07 \\
\hline $2,1,2$ & -2171.66 \\
\hline $1,0,2$ & -2175.97 \\
\hline $2,3,2$ & -2136.32 \\
\hline
\end{tabular}

Table 1: AICc values of dataset of "Emami Limited" for different models

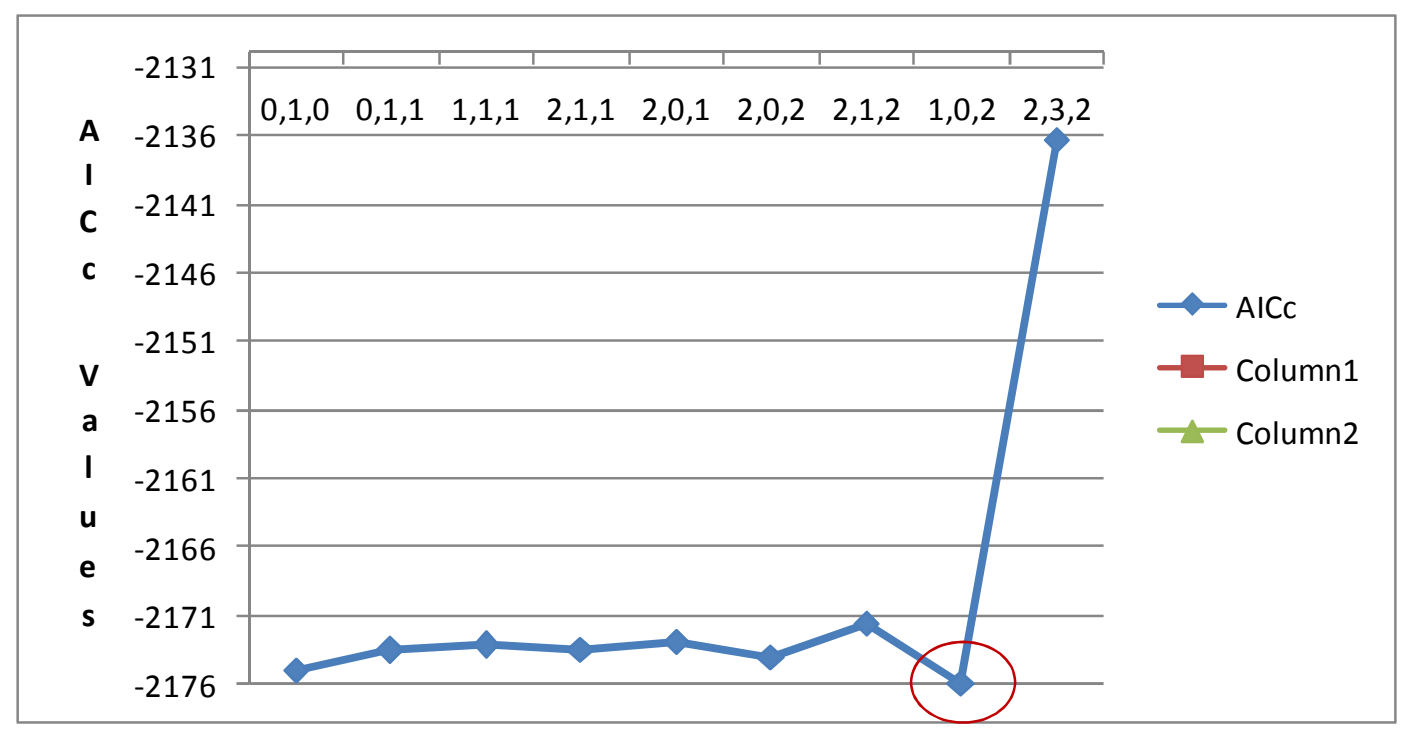

Figure 1: AICc values for different models

Depending on AICc, model ARIMA(1,0,2) is selected for the above mentioned stock.

\subsubsection{Parameter Estimation:}

The parameters estimated as per the model identified are as follows: 
International Journal of Computer Science, Engineering and Applications (IJCSEA) Vol.4, No.2, April 2014

\begin{tabular}{|l|l|l|l|l|}
\hline Coefficients & & & & \\
\hline & ar1 & ma1 & ma2 & Intercept \\
\hline & 0.9863 & -0.0158 & -0.082 & 6.2366 \\
\hline S.E. & 0.0073 & 0.0453 & 0.045 & 0.0714 \\
\hline
\end{tabular}

Table 2: Estimated parameters for ARIMA $(1,0,2)$ for dataset of Emami Limited

The coefficients show the AR and MA terms of the particular ARIMA model. S.E. denotes the standard error.

\subsubsection{Checking the model:}

The partial autocorrelation function (PACF) identifies the appropriate lag $p$ in an extended ARIMA(p,d,q) model. Both ACF and PACF are used to check whether the model selected by AICc criterion is appropriate.

\begin{tabular}{|l|l|l|}
\hline Model & ACF & PACF \\
\hline MA (q): moving average of order q & Cuts off after lag q & Dies Down \\
\hline AR (p): autoregressive of order p & Dies Down & Cuts off after lag $\mathrm{p}$ \\
\hline $\begin{array}{l}\text { ARMA (p,q): mixed autoregressive- } \\
\text { moving average of order (p, } q)\end{array}$ & Dies Down & Dies Down \\
\hline $\begin{array}{l}\text { ARIMA (p, d, q): Autoregressive } \\
\text { (p,egrated Moving Average of order }\end{array}$ & Dies Down & Dies Down \\
\hline
\end{tabular}

Table 3: Role of ACF and PACF in selecting models

The identified model does not show significant lag in ACF and PACF of the residuals, hence the identified model was selected to analyze the aforementioned dataset.

After identifying the model, it was fitting for twenty three months', eighteen months', twelve months' and six months' stock prices and accordingly next thirty days' data were predicted. 
International Journal of Computer Science, Engineering and Applications (IJCSEA) Vol.4, No.2, April 2014

\subsection{STEP II: MEASURING THE ACCURACY OF PREDICTION AND STANDARD DEVIATION OF ACCURACY:}

After prediction, the accuracy was measured in percentage. The actual data for 30 days that were predicted previously was collected from the same source and compared to measure the accuracy. We have used Mean Absolute Error (MAE) [17] method to compute the accuracy. The method is elaborated below:

i) Firstly, the predicted values and the actual values are stored in a single matrix with two columns, namely PredictedVal and ActualVal containing the predicted and original values respectively.

ii) Then the error between the 2 columns are computed,

err $=\mid$ ActualVal-PredictedVal $\mid$

iii) Next, we calculate the accuracy by,

acc $=1$-err/ActualVal

iv) Next, the percentage of accuracy is calculated by, (acc*100) \%.

v) The individual accuracies are averaged to get the accuracy of for each sector.

vi) It is done for six, twelve, eighteen and twenty three months' training data separately.

Lastly, we check the standard deviation of the accuracy of forecasting for each sector to get precise results. A smaller standard deviation indicates data members have closer value of the mean and a larger standard deviation denotes that the data are deviated from the mean to larger extent.

\subsection{STEP III: PAIRED T-TeSTING:}

We conducted paired t-test for each pair of accuracies (all combinations possible) to test whether the difference between accuracy of prediction for different training datasets is significant. A paired t-test checks the difference between paired values within two samples. Each test produces a p-value. The p-values for each pair tests whether the coefficient of the null hypothesis is zero. A smaller p-value indicates that the null hypothesis can be rejected, and a higher p-value suggests that changes in the predictor are statistically insignificant.

Here, our null hypothesis is, the changes in the accuracy for different size of training datasets is not significant. If a p - value is lesser than this will be rejected, and it will be concluded that the differences between accuracy of prediction for different sizes of data is significant. Else, it will be accepted. The results are displayed in table 13.

\section{EXPERIMENTAL RESULTS}

The high price of stocks is taken into consideration for implementation. All the implementation works are done through R [20]. All the series are stationary.

The accuracy of prediction for different sectors are computed by averaging the accuracies obtained by the algorithm of top eight companies in that sector. The result is given below in Table 3. 
International Journal of Computer Science, Engineering and Applications (IJCSEA) Vol.4, No.2, April 2014

\begin{tabular}{|l|l|l|l|l|}
\hline Sector & $\begin{array}{l}\text { Accuracy of } \\
\text { prediction (in \%) } \\
\text { for twenty three } \\
\text { months' training } \\
\text { data }\end{array}$ & $\begin{array}{l}\text { Accuracy of } \\
\text { prediction (in } \\
\text { (ig) for } \\
\text { eighteen } \\
\text { months' } \\
\text { training data }\end{array}$ & $\begin{array}{l}\text { Accuracy of } \\
\text { prediction (in \%) for } \\
\text { twelve months' } \\
\text { training data }\end{array}$ & $\begin{array}{l}\text { Accuracy of } \\
\text { prediction (in } \\
\% \text { for six } \\
\text { months' training } \\
\text { data }\end{array}$ \\
\hline $\begin{array}{l}\text { 1. Information } \\
\text { Technology (IT) }\end{array}$ & 91.06 & 93.77 & 93.79 & 94.03 \\
\hline 2. Infrastructure & 91.29 & 91.56 & 91.58 & 90.88 \\
\hline 3. Bank & 90.51 & 89.37 & 89.57 & 88.54 \\
\hline 4. Automobile & 87.89 & 85.32 & 85.78 & 85.91 \\
\hline 5. Power & 92.28 & 92.21 & 92.21 & 92.03 \\
\hline $\begin{array}{l}\text { 6. Fast Moving } \\
\text { Consumer Goods } \\
\text { (FMCG) }\end{array}$ & 95.93 & 95.70 & 95.44 & 95.85 \\
\hline 7. Steel & 90.46 & 89.14 & 90.29 & 89.41 \\
\hline
\end{tabular}

Table 4: Accuracy of prediction using ARIMA for seven sectors

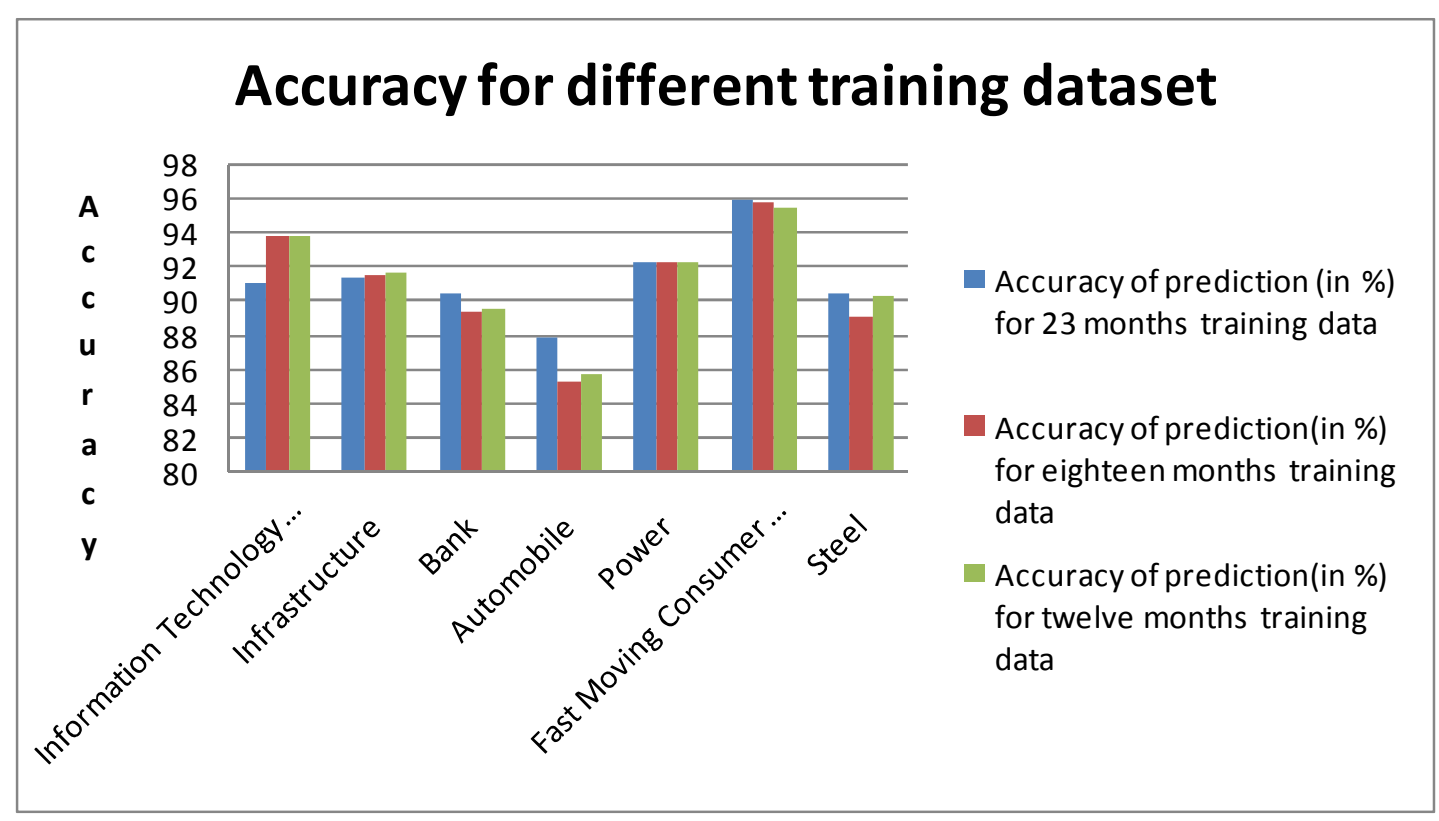

Figure 2: Accuracy for different training data sets

Next we show the result for each company in table 5,6,7,8,9,10,11 for the automobile sector, banking sector, infrastructure sector, steel sector, FMCG sector, IT sector and power sector respectively. 
International Journal of Computer Science, Engineering and Applications (IJCSEA) Vol.4, No.2, April 2014

1. Automobile sector:

\begin{tabular}{|l|l|l|l|l|}
\hline Company name & $\begin{array}{l}\text { Accuracy of } \\
\text { prediction(in \%) } \\
\text { for twenty three } \\
\text { months training } \\
\text { data }\end{array}$ & $\begin{array}{l}\text { Accuracy of } \\
\text { prediction(in \%) } \\
\text { for eighteen } \\
\text { months training } \\
\text { data }\end{array}$ & $\begin{array}{l}\text { Accuracy of for twelve } \\
\text { prediction(in } \\
\text { \%) for } \\
\text { months' } \\
\text { training data }\end{array}$ & $\begin{array}{l}\text { Accuracy of } \\
\text { prediction(in \%) } \\
\text { for six months' } \\
\text { training data }\end{array}$ \\
\hline Ashok Leyland & 85.99 & 85.32 & 85.66 & 84.37 \\
\hline Bajaj & 93.02 & 93.82 & 94.72 & 94.45 \\
\hline Hero Moto Corp. & 92.23 & 92.09 & 92.23 & 95.80 \\
\hline Hind Motors & 86.67 & 91.74 & 93.05 & 93.41 \\
\hline $\begin{array}{l}\text { Mahindra } \\
\text { Mahindra }\end{array}$ & 94.84 & 94.26 & 94.45 & 94.26 \\
\hline Maruti Suzuki & 84.99 & 85.04 & 78.85 & 85.65 \\
\hline Tata Motors & 95.58 & 95.32 & 95.73 & 94.45 \\
\hline TVS & 69.78 & 44.31 & 51.55 & 43.88 \\
\hline
\end{tabular}

Table 5.Results for automobile sector

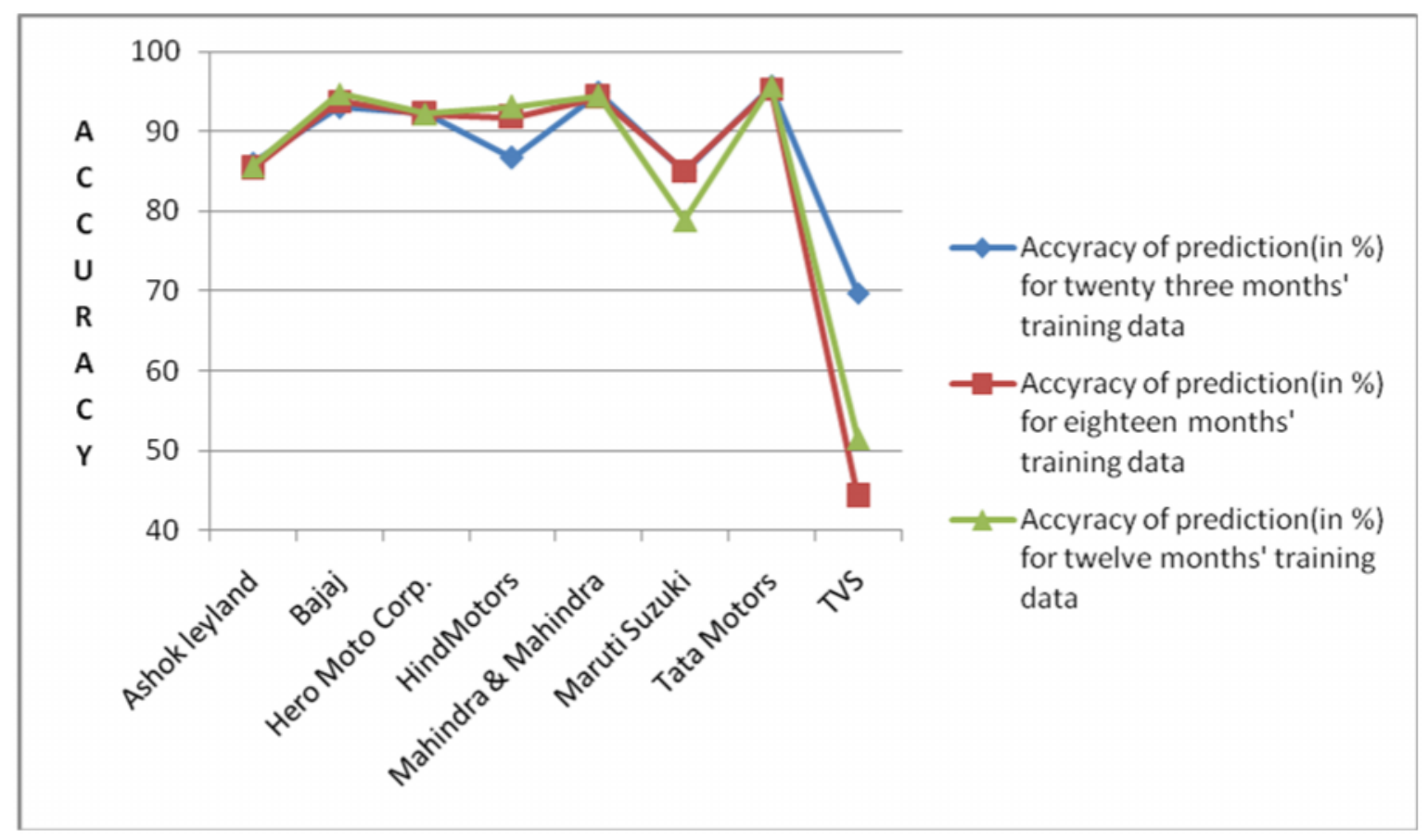

Figure 3: accuracy for automobile sector 
International Journal of Computer Science, Engineering and Applications (IJCSEA) Vol.4, No.2, April 2014

\section{Banking Sector:}

\begin{tabular}{|l|l|l|l|l|}
\hline Company name & $\begin{array}{l}\text { Accuracy of } \\
\text { prediction (in } \\
\text { \%) for twenty } \\
\text { three months' } \\
\text { training data }\end{array}$ & $\begin{array}{l}\text { Accuracy of } \\
\text { prediction (in \%) for } \\
\text { eighteen months' } \\
\text { training data }\end{array}$ & $\begin{array}{l}\text { Accuracy of } \\
\text { prediction (in \%) } \\
\text { for twelve } \\
\text { months } \\
\text { data }\end{array}$ & $\begin{array}{l}\text { Accuracy } \\
\text { prediction (in \%) } \\
\text { for six months' } \\
\text { training data } \\
\text { traing }\end{array}$ \\
\hline Axis bank & 85.49 & 85.48 & 86.64 & 83.94 \\
\hline $\begin{array}{l}\text { State bank of } \\
\text { India }\end{array}$ & 92.70 & 85.41 & 85.39 & 85.31 \\
\hline Bank of India & 87.34 & 87.79 & 87.45 & 87.23 \\
\hline Bank of Baroda & 84.49 & 83.98 & 84.86 & 82.74 \\
\hline HDFC & 92.98 & 90.94 & 90.90 & 90.14 \\
\hline ICICI & 88.26 & 88.97 & 89.16 & 85.36 \\
\hline IDBI & 94.94 & 94.96 & 94.71 & 96.14 \\
\hline PSB & 97.86 & 97.38 & 97.46 & 97.45 \\
\hline
\end{tabular}

Table 6 Results for banking sector

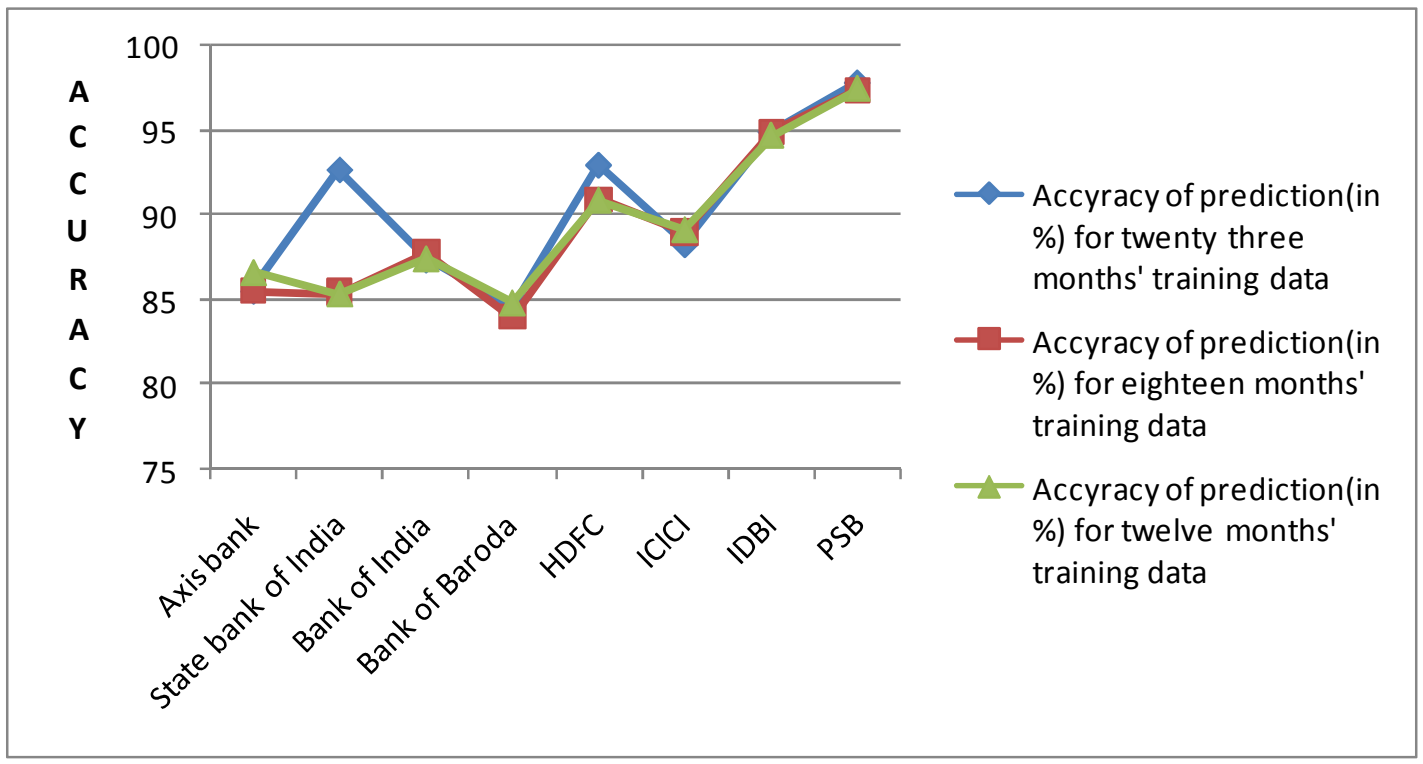

Figure 4:Accuracy for Banking sector 
International Journal of Computer Science, Engineering and Applications (IJCSEA) Vol.4, No.2, April 2014

\section{Infrastructure sector:}

\begin{tabular}{|c|c|c|c|c|}
\hline Company name & $\begin{array}{l}\text { Accuracy of } \\
\text { prediction (in \%) } \\
\text { for twenty three } \\
\text { months' training } \\
\text { data }\end{array}$ & $\begin{array}{lr}\text { Accuracy } & \text { of } \\
\text { prediction } & \text { (in \%) } \\
\text { for } & \text { eighteen } \\
\text { months' } & \text { training } \\
\text { data } & \end{array}$ & $\begin{array}{l}\text { Accuracy of } \\
\text { prediction (in } \\
\% \text { ) for twelve } \\
\text { months' training } \\
\text { data }\end{array}$ & $\begin{array}{l}\text { Accuracy of } \\
\text { prediction (in \%) } \\
\text { for six months' } \\
\text { training data }\end{array}$ \\
\hline Ramky & 82.84 & 91.01 & 91.93 & 92.08 \\
\hline JPInfratech & 95.19 & 95.51 & 96.57 & 95.97 \\
\hline RelIndia & 92.13 & 91.48 & 91.94 & 91.21 \\
\hline GMRInfra & 94.13 & 91.97 & 91.59 & 90.56 \\
\hline DLF & 90.34 & 90.09 & 89.50 & 89.09 \\
\hline Simplex & 84.84 & 85.03 & 84.82 & 78.56 \\
\hline Gammon & 96.08 & 96.15 & 96.12 & 95.85 \\
\hline GodrejProperties & 89.81 & 91.23 & 90.15 & 93.75 \\
\hline
\end{tabular}

Table 7. Results for infrastructure sector

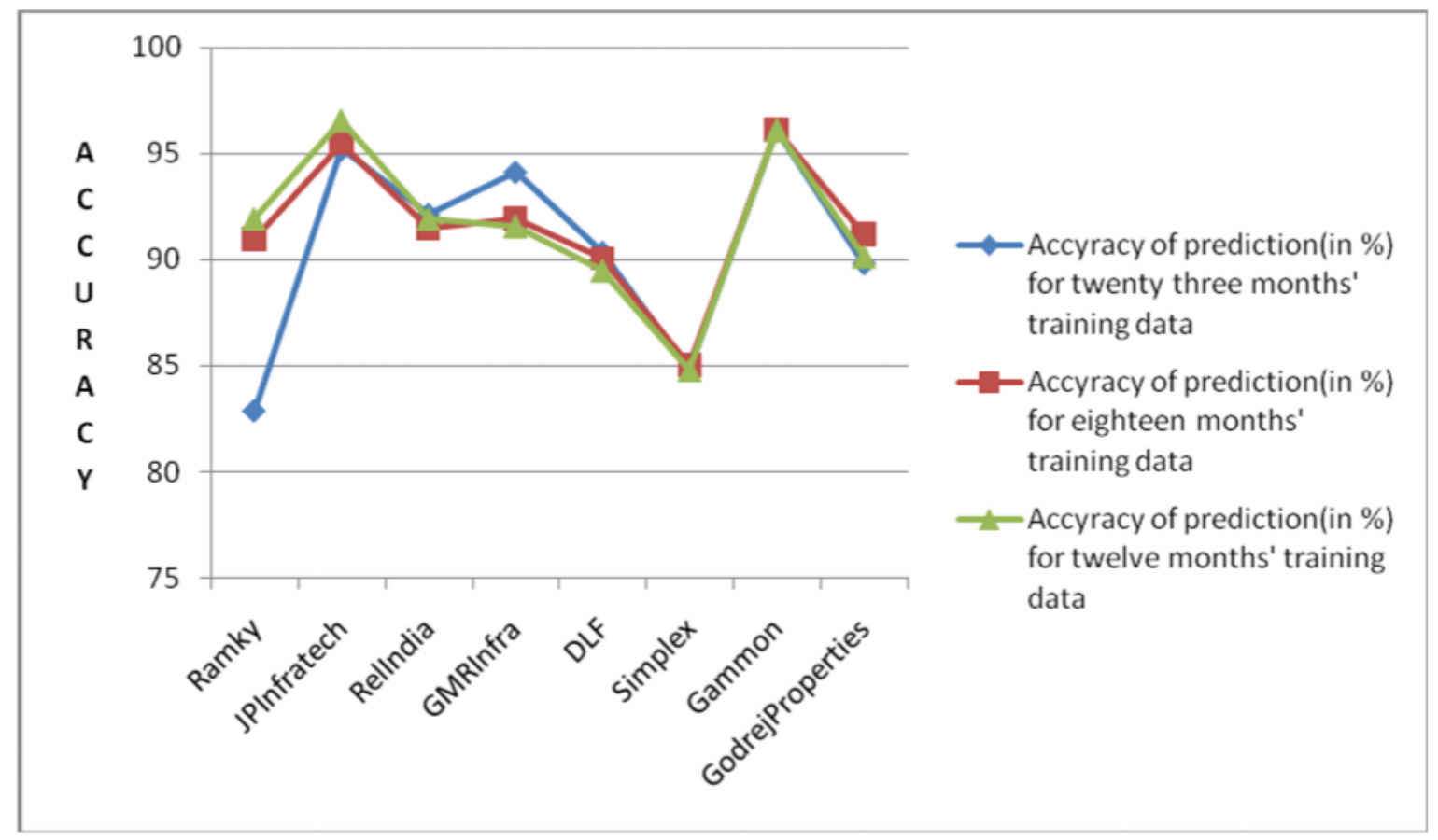

Figure 5:Accuracy for the infrastructure sector 
International Journal of Computer Science, Engineering and Applications (IJCSEA) Vol.4, No.2, April 2014

4. Steel sector:

\begin{tabular}{|l|l|l|l|l|}
\hline Company name & $\begin{array}{l}\text { Accuracy of } \\
\text { prediction (in \%) } \\
\text { for twenty three } \\
\text { months training } \\
\text { data }\end{array}$ & $\begin{array}{l}\text { Accuracy of } \\
\text { prediction (in \%) } \\
\text { for eighteen } \\
\text { months' training } \\
\text { data }\end{array}$ & $\begin{array}{l}\text { Accuracy of } \\
\text { prediction } \\
\text { (in \%) for } \\
\text { twelve } \\
\text { months' } \\
\text { training data }\end{array}$ & $\begin{array}{l}\text { Accuracy of } \\
\text { prediction (in \%) } \\
\text { for six months' } \\
\text { training data }\end{array}$ \\
\hline Tata Steel & 95.16 & 96.43 & 96.33 & 96.27 \\
\hline Jindal Steel & 94.99 & 95.96 & 95.76 & 94.07 \\
\hline VSSL & 77.75 & 76.94 & 77.83 & 78.53 \\
\hline Visa Steel & 96.75 & 95.56 & 95.47 & 89.66 \\
\hline SAIL & 93.31 & 93.15 & 93.47 & 93.45 \\
\hline Bhusan Steel & 98.94 & 97.67 & 98.17 & 96.99 \\
\hline Adhunik Steel & 78.89 & 74.13 & 74.51 & 75.39 \\
\hline Sal Steel & 87.91 & 90.51 & 90.84 & 90.91 \\
\hline
\end{tabular}

Table 8. Results for steel sector

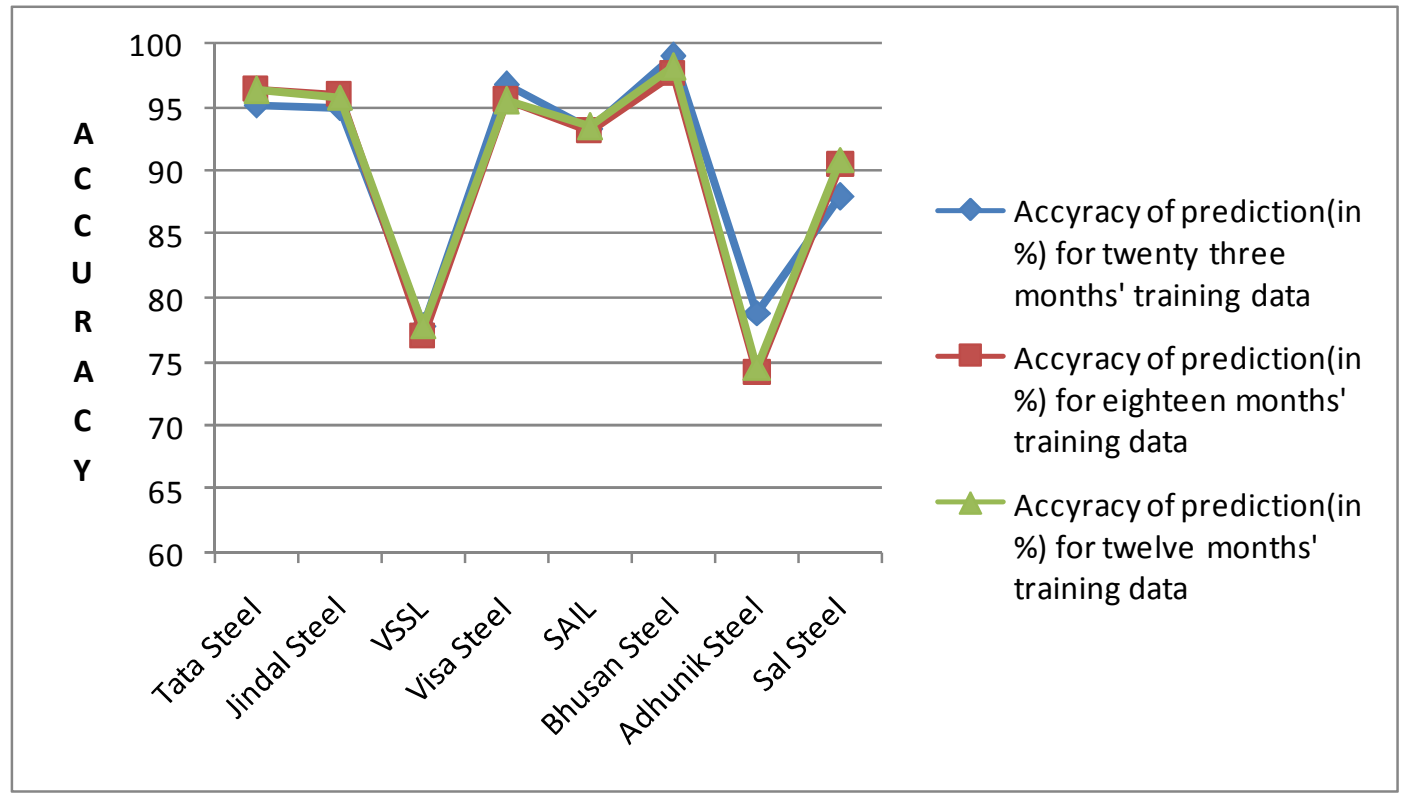

Figure 6. Accuracy for steel sector 


\section{FMCG:}

\begin{tabular}{|l|l|l|l|l|}
\hline Company name & $\begin{array}{l}\text { Accuracy of } \\
\text { prediction (in \%) } \\
\text { for twenty three } \\
\text { months' training } \\
\text { data }\end{array}$ & $\begin{array}{l}\text { Accuracy of } \\
\text { prediction (in \%) } \\
\text { for eighteen } \\
\text { months training } \\
\text { data }\end{array}$ & $\begin{array}{l}\text { Accuracy of } \\
\text { prediction (in } \\
\text { \%) for twelve } \\
\text { months' } \\
\text { training data }\end{array}$ & $\begin{array}{l}\text { Accuracy of } \\
\text { prediction for six } \\
\text { \%onths' } \\
\text { monining data } \\
\text { traing }\end{array}$ \\
\hline $\begin{array}{l}\text { Hindustan } \\
\text { Unilever }\end{array}$ & 96.36 & 96.90 & 97.04 & 97.66 \\
\hline Gillette & 96.59 & 95.79 & 94.86 & 96.05 \\
\hline Colpal & 97.56 & 98.41 & 98.55 & 96.58 \\
\hline ITC & 92.05 & 92.03 & 93.38 & 94.01 \\
\hline Godrej & 95.16 & 95.11 & 93.80 & 94.43 \\
\hline Emami & 96.15 & 95.28 & 94.82 & 97.20 \\
\hline Nestle India & 97.28 & 96.99 & 96.39 & 95.29 \\
\hline Dabur & 96.27 & 95.11 & 94.68 & 95.56 \\
\hline
\end{tabular}

Table 9. Results for FMCG sector

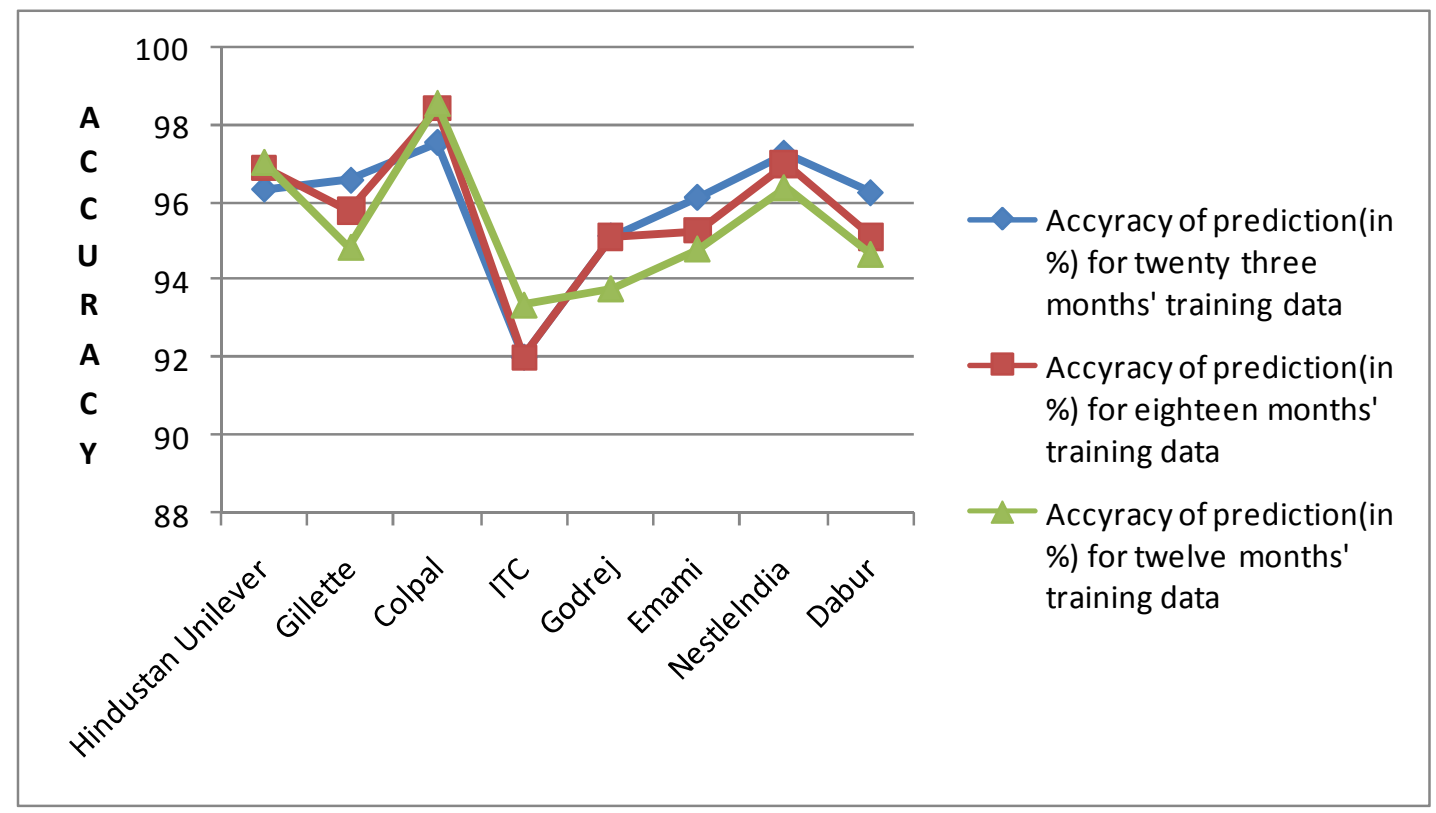

Figure 7: accuracy for FMCG sector 
6. IT:

\begin{tabular}{|l|l|l|l|l|}
\hline Company name & $\begin{array}{l}\text { Accuracy of } \\
\text { prediction (in \%) } \\
\text { for twenty three } \\
\text { month' training } \\
\text { data }\end{array}$ & $\begin{array}{l}\text { Accuracy of } \\
\text { prediction (in \%) } \\
\text { for eighteen } \\
\text { months training } \\
\text { data }\end{array}$ & $\begin{array}{l}\text { Accuracy of } \\
\text { prediction } \\
\text { in for for } \\
\text { twelve } \\
\text { months' } \\
\text { training data }\end{array}$ & $\begin{array}{l}\text { Accuracy of } \\
\text { prediction (in \%) } \\
\text { for six months } \\
\text { training data }\end{array}$ \\
\hline $\begin{array}{l}\text { Tata Consultancy } \\
\text { service }\end{array}$ & 98.12 & 98.22 & 98.32 & 98.38 \\
\hline Infosys & 93.85 & 93.48 & 93.68 & 93.54 \\
\hline Tech Mahindra & 98.36 & 98.17 & 98.34 & 98.39 \\
\hline Wipro & 97.56 & 97.56 & 96.04 & 97.38 \\
\hline HCLTech & 97.48 & 97.23 & 97.51 & 97.11 \\
\hline Polaris & 78.83 & 77.46 & 78.38 & 79.16 \\
\hline OFSS & 97.65 & 97.68 & 97.44 & 97.36 \\
\hline Mindtree & 90.81 & 90.61 & 90.61 & 90.35 \\
\hline
\end{tabular}

Table 10. Results for IT sector

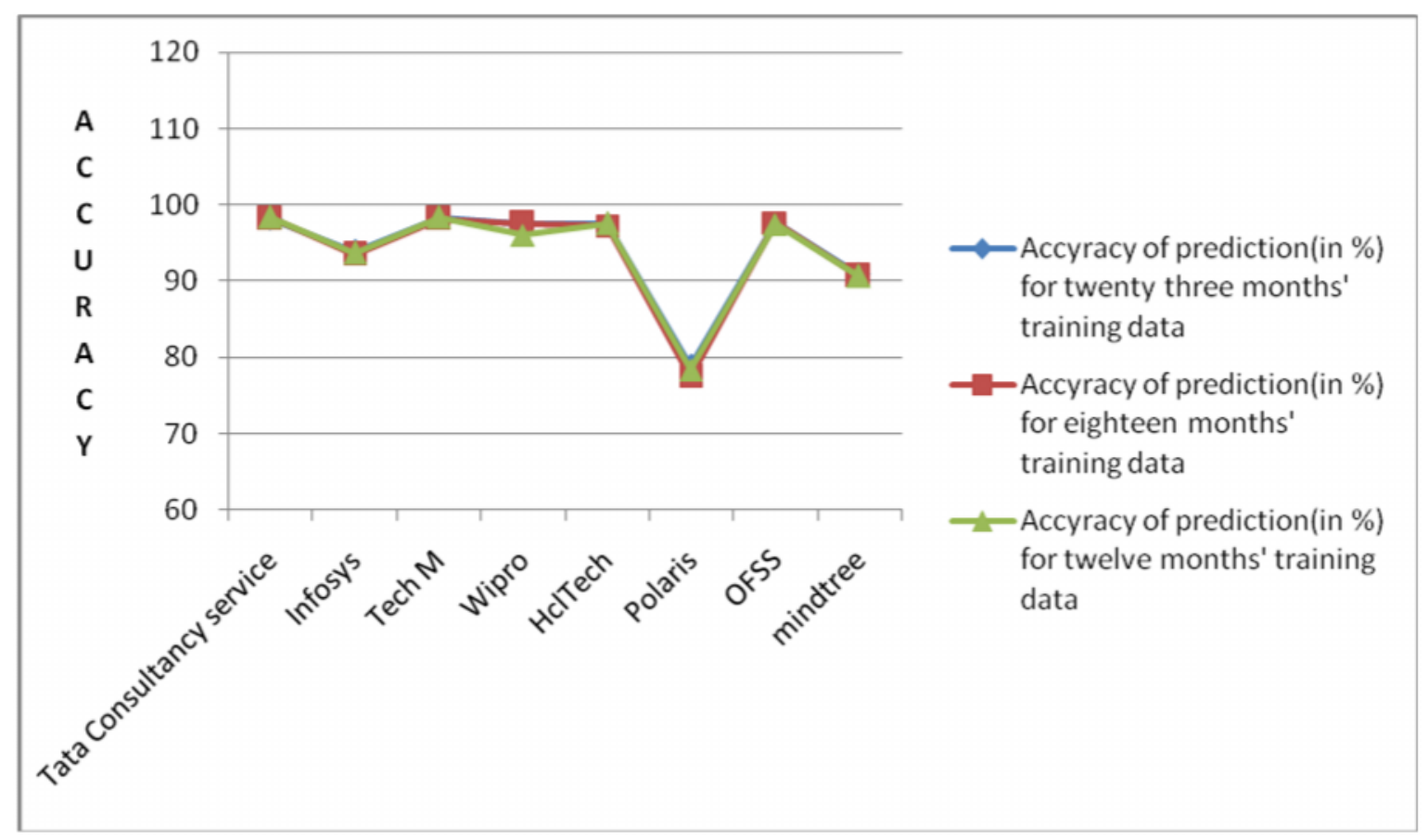

Figure 8: accuracy of IT sector 
International Journal of Computer Science, Engineering and Applications (IJCSEA) Vol.4, No.2, April 2014

7. Power:

\begin{tabular}{|l|l|l|l|l|}
\hline Company name & $\begin{array}{l}\text { Accuracy of } \\
\text { prediction (in \%) } \\
\text { for twenty three } \\
\text { months training } \\
\text { data }\end{array}$ & $\begin{array}{l}\text { Accuracy of } \\
\text { prediction (in } \\
\text { eighteen for } \\
\text { months' } \\
\text { training data }\end{array}$ & $\begin{array}{l}\text { Accuracy of } \\
\text { prediction for twelve } \\
\text { \%) for } \\
\text { months' } \\
\text { training data }\end{array}$ & $\begin{array}{l}\text { Accuracy of } \\
\text { prediction (in \%) } \\
\text { for six months' } \\
\text { training data }\end{array}$ \\
\hline Tata Power & 97.82 & 97.65 & 97.54 & 97.02 \\
\hline Reliance Power & 96.84 & 97.47 & 96.41 & 97.25 \\
\hline Birla Power & 86.61 & 86.41 & 86.69 & 86.67 \\
\hline NTPC & 84.18 & 85.23 & 83.34 & 85.58 \\
\hline GPIL & 93.43 & 93.40 & 94.77 & 96.28 \\
\hline GIPCL & 95.36 & 94.93 & 95.38 & 95.07 \\
\hline Powergrid & 96.26 & 95.66 & 96.19 & 95.89 \\
\hline JP Power & 87.74 & 86.98 & 87.33 & 82.48 \\
\hline
\end{tabular}

Table 11. Results for power sector

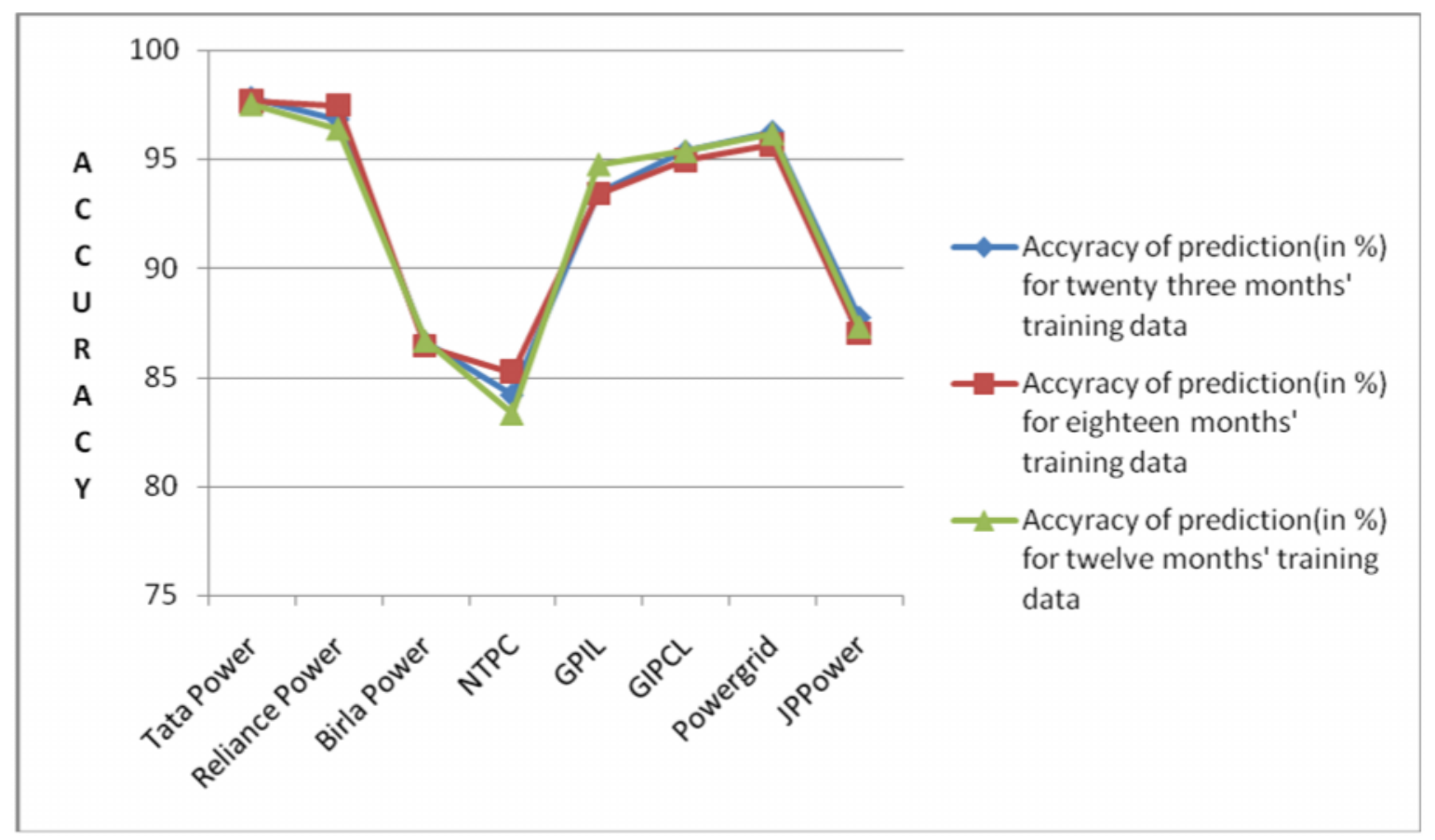

Figure 9: accuracy for Power sector 
In the next table, we show the standard deviation of accuracy of prediction for each sector.

\begin{tabular}{|l|l|l|l|l|}
\hline Sector & $\begin{array}{l}\text { Standard } \\
\text { deviation of } \\
\text { twenty three } \\
\text { months' training } \\
\text { data }\end{array}$ & $\begin{array}{l}\text { Standard } \\
\text { deviation of } \\
\text { eighteen months' } \\
\text { training data }\end{array}$ & $\begin{array}{l}\text { Standard } \\
\text { deviation of } \\
\text { twelve } \\
\text { months' } \\
\text { training data }\end{array}$ & $\begin{array}{l}\text { Standard } \\
\text { deviation of six } \\
\text { months' training } \\
\text { data }\end{array}$ \\
\hline Automobile & 8.401289 & 16.99188 & 14.96798 & 17.47848 \\
\hline Banking & 8.238547 & 15.67122 & 13.36196 & 15.77012 \\
\hline Infrastructure & 5.073215 & 3.744663 & 4.009234 & 5.63259 \\
\hline Steel & 7.619857 & 8.663484 & 8.441142 & 7.718103 \\
\hline $\begin{array}{l}\text { Fast Moving } \\
\text { Consumer } \\
\text { Goods }\end{array}$ & 3.123484 & 2.468907 & 2.240957 & 2.035353 \\
\hline $\begin{array}{l}\text { Information } \\
\text { Technology }\end{array}$ & 6.310874 & 6.693157 & 6.341761 & 6.193422 \\
\hline Power & 4.980284 & 4.873199 & 5.168635 & 5.683261 \\
\hline
\end{tabular}

Table 12: Standard deviation of accuracy of forecasting for different sectors

\begin{tabular}{|l|l|l|l|}
\hline & $\begin{array}{l}\text { Twenty three } \\
\text { months' data }\end{array}$ & $\begin{array}{l}\text { Eighteen months' } \\
\text { data }\end{array}$ & $\begin{array}{l}\text { Twelve months' } \\
\text { data }\end{array}$ \\
\hline $\begin{array}{l}\text { Eighteen } \\
\text { months' data }\end{array}$ & 0.2902 & \multicolumn{1}{|c|}{-} & - \\
\hline $\begin{array}{l}\text { Twelve months' } \\
\text { data }\end{array}$ & 0.3138 & 0.5896 & - \\
\hline Six months' data & 0.1983 & 0.3874 & 0.3053 \\
\hline
\end{tabular}

Table 13: Null hypothesis testing of accuracy of forecasting for different training data

\section{Conclusion:}

In this paper, we have conducted a study on fifty six stocks from seven sectors. All the stocks that are selected are listed in National Stock Exchange (NSE) [19]. We have selected twenty three months' of data for the set empirical study. We have evaluated the accuracy of the ARIMA model in predicting the stock prices. AICc has been used to select the best ARIMA model. In our study, 
we have also changed the time period of previous or historic data and studied its effect on accuracy.

For all the sectors, Accuracy of ARIMA model in predicting stock prices is above $85 \%$, which indicates that ARIMA gives good accuracy of prediction. If we discuss about specific sectors, forecasting stocks in FMCG sector using ARIMA model give result with best accuracy. On the other hand accuracy of predictions for the banking sector and automobile sector using ARIMA model is lower as compared to that of other sectors. Hence, we need a better model for forecasting stocks of the companies in aforementioned sector.

From the standard deviations of accuracy of forecasting of seven sectors, we see that Automobile sector, steel sector and the banking sector has a high standard deviation which means the values are spread over a large range, and there might be some stocks for which ARIMA model does not produce good results. For Information Technology sector, the standard deviation is not too low or not too high, whereas we are getting an above $90 \%$ accuracy in prediction for this sector. There may be a possibility that stock prices of companies of IT sector vary within a high range due to changes in value of the dollar and other factors.

We see that p-values for all possible combinations are high, hence we cannot reject the null hypothesis, i.e. the null hypothesis will be accepted which is, the changes in the accuracy for different size of training datasets is not significant.

\section{REFERENCES}

[1] Chen, S., et al. "The time series forecasting: from the aspect of network." arXiv preprint arXiv:1403.1713 (2014).

[2] Devi, B. Uma, D. Sundar, and P. Alli. "An Effective Time Series Analysis for Stock Trend Prediction Using ARIMA Model for Nifty Midcap-50."

[3] Box, George EP, and George C. Tiao. "Intervention analysis with applications to economic and environmental problems." Journal of the American Statistical Association 70.349 (1975): 70-79.

[4] Kofi agyarko ababio, June 2012, "Comparative study of stock price forecasting using arima and arimax models".

[5] L---Stern Group Ly Pham, Time Series Analysis with ARIMA - ARCH/GARCH model in R

[6] Al Wadia, Mohd Tahir Ismail S, "Selecting Wavelet Transforms Model in Forecasting Financial Time Series Data Based on ARIMA Model”, Applied Mathematical Sciences, Vol. 5, 2011, no. 7, 315 326

[7] Anderson, David Raymond. Model based inference in the life sciences: a primer on evidence. New York: Springer, 2008.

[8] Chatfield, Chris. The analysis of time series: an introduction. CRC press, 2013.

[9] Christodoulos, Charisios, Christos Michalakelis, and Dimitris Varoutas. "Forecasting with limited data: Combining ARIMA and diffusion models."Technological forecasting and social change 77.4 (2010): 558-565.

[10] Pai, Ping-Feng, and Wei-Chiang Hong. "An improved neural network model in forecasting arrivals." Annals of Tourism Research 32.4 (2005): 1138-1141.

[11] Nayak, S. C., and B. B. Mishra. "A Neuro-Genetic Technique for Index Prediction.

[12] Liang, Jiuzhen, Wei Song, and Mei Wang. "Stock price prediction based on procedural neural networks." Advances in Artificial Neural Systems 2011 (2011): 6.

[13] Jarrett, Jeffrey E., and Eric Kyper. "ARIMA modeling with intervention to forecast and analyze chinese stock prices." International Journal of Engineering Business Management 3.3 (2011): 53-58. 
International Journal of Computer Science, Engineering and Applications (IJCSEA) Vol.4, No.2, April 2014

[14] Yang, Yuhong. "Can the strengths of AIC and BIC be shared? A conflict between model indentification and regression estimation." Biometrika 92.4 (2005): 937-950.

[15] Tseng, Fang-Mei, et al. "Fuzzy ARIMA model for forecasting the foreign exchange market." Fuzzy sets and systems 118.1 (2001): 9-19.

[16] Contreras, J., Espinola, R., Nogales, F. J., \& Conejo, A. J. (2003). ARIMA models to predict next-day electricity prices. Power Systems, IEEE Transactions on, 18(3), 1014-1020.

[17] Willmott, Cort J., and Kenji Matsuura. "Advantages of the mean absolute error (MAE) over the root mean square error(RMSE) in assessing average model performance." Climate Research 30.1 (2005): 79.

[18] A. Pankratz, Forecasting with Dynamic Regression models, Wiley Interscience, 1991.

[19] http://www.nseindia.com/products/content/equities/equities/eq_security.htm.

[20] R Development Core Team (2008). R: A language and environment for statistical computing. R Foundation for Statistical Computing, Vienna, Austria. ISBN 3-900051-07-0, URL http://www.Rproject.org. 